\title{
Compound flood impact of water level and rainfall during tropical cyclone period in a coastal city: The case of Shanghai
}

Hanqing $\mathrm{Xu}^{1,2,3}$, Zhan Tian ${ }^{2}$, Laixiang Sun ${ }^{4}$, Qinghua Ye ${ }^{3,5}$, Elisa Ragno ${ }^{3}$, Jeremy Bricker ${ }^{3,6}$, Ganquan $\mathrm{Mao}^{2}$, Jinkai Tan ${ }^{7}$, Jun Wang ${ }^{1}$, Qian $\mathrm{Ke}^{3}$, Shuai Wang ${ }^{8}$, Ralf Toumi ${ }^{8}$

$5 \quad{ }^{1}$ Key Laboratory of Geographic Information Science (Ministry of Education), East China Normal University, Shanghai, China

${ }^{2}$ School of Environmental Science and Engineering, Southern University of Science and Technology, Shenzhen, China

${ }^{3}$ Department of Hydraulic Engineering, Faculty of Civil Engineering and Geosciences, University of Technology, Delft, Netherlands

$10 \quad{ }^{4}$ Department of Geographical Sciences, University of Maryland, College Park, USA

${ }^{5}$ Deltares, Delft, Netherlands

${ }^{6}$ Department of Civil and Environmental Engineering, University of Michigan, Ann Arbor, Michigan, USA

${ }^{7}$ School of Atmospheric Sciences, and Key Laboratory of Tropical Atmosphere-Ocean System (Ministry of Education), Sun Yat-sen University, Zhuhai, China

$15{ }^{8}$ Department of Physics, Imperial College London, London, UK

Correspondence to: Zhan Tian (tianz@ sustech.edu.cn); Jun Wang (jwang@geo.ecnu.edu.cn)

Abstract. Compound flooding is generated when two or more flood drivers occur simultaneously or in close succession. Multiple drivers can amplify each other and lead to greater impacts than when they occur in isolation. A better understanding of the interdependence between flood drivers will facilitate a more accurate assessment of compound flood risk in the coastal regions. This study employed the Delft3D-Flow Flexible Mesh model to simulate the peak coastal water level, consisting of storm surge, astronomical tide, and the relative sea level rise (RSLR) in Shanghai over 1961-2018. It then applies a copulabased methodology to calculate the joint probability of peak water level and rainfall during historical tropical cyclones (TCs) and to calculate the marginal contribution of each driver. The results indicate that the astronomic tide is the leading driver to peak water level, followed by the contribution of storm surge. In a longer term, the RSLR has significantly amplified the peak water level. This framework could be applied to other coastal cities which face the similar constraint of unavailable water level records.

\section{Introduction}

Compound flooding is generated when two or more flood drivers, e.g., water level, rainfall, and high river discharges, occur simultaneously or in close succession. Such flood drivers can amplify each other and lead to greater impacts than when they occur in isolation (Leonard et al., 2014; Zscheischler et al., 2018; Visser-Quinn et al., 2019; Chao et al., 2021). Coastal cities like Shanghai are particularly prone to compound flooding associated with tropical cyclones (TCs), which often bring heavy rainfall and storm surge. For a more accurate assessment of compound flood in the coastal regions, a thorough understanding of the interdependence between multiple flood-drivers is necessary. In other words, an enriched knowledge about the 
dynamic interaction between flood-drivers would significantly improve the quantification of compound flooding risks in estuarine environments (Feng and Beighley, 2020). As such, the joint probability theory has been incorporated into the analysis of compound flood risk to take the advantage of the Sklar's Theorem that any multivariate joint cumulative distribution function can be expressed in terms of univariate marginal distribution functions and a copula which describes the structure of dependency between the variables (M. Sklar, 1959; Bevacqua et al., 2019).

Shanghai is the largest and most developed coastal megacity in China. Rainstorm and storm surge caused by typhoon from June to October often cause substantial losses ( $\mathrm{Li}$ et al., 2018; Yin et al., 2021). For example, extreme storm flooding caused nearly 30 thousand casualties in 1905 (Li et al., 2019). In 1962, storm flooding inundated half of the downtown region for nearly 10 days due to 46 failures along the floodwalls of the Huangpu River and its branches and led to huge losses of 1/6 of the total GDP in Shanghai (Ke, 2014). In 1997, Typhoon Winnie killed seven people and flooded more than 5,000 households due to the extreme storm surge and rainfall (Ke et al., 2021). Although the construction of flood control measures

45 in the past 50 years (especially after the typhoon Winnie in 1997) has effectively reduced the risk of storm surge and rainstorm floods, Typhoon Matsa in 2005, Typhoon Fitow in 2013, and Typhoon Lekima in 2019 also brought significant damage to Shanghai (Du et al., 2020). Therefore, compare the encounters of rainfall and storm surge during typhoon season is important to understand the frequency of compound flooding in Shanghai. However, owing to the unavailability of water level records during typhoon events, there is no research that has been able to calculate the joint probability of peak water

50 level and rainfall during historical TCs and to calculate the marginal contribution of each driver as we have done in this research.

The copula method is widely use in statistics to model the interdependence between two or more variables (Anandalekshmi et al., 2019; Balistrocchi et al., 2019; Xu, P. et al., 2019). Recent research using the copula model emphasizes the importance of studying the combined effects of rainfall and water level processes in estuaries and coastal regions. For example, $\mathrm{Xu}, \mathrm{H}$. et

55 al. (2018) showed the existence of some positive dependences between rainfall and water level in a coastal city of Hainan Island, while the water level poses an additional risk of flooding. The studies of both Xu, P. et al (2019) and Xu. H. et al. (2018) confirmed that the is a promising tool for studying multivariate problems in hydrology and coastal engineering. However, when applying the copula-based methods to 3 dimensions, controversies arise and uncertainty can become explosive (Bevacqua et al., 2017; Santos et al., 2021). The univariate flood driver cannot provide an accurate evaluation if 60 the underlying drivers are modelled as independent extreme events (Li et al., 2016; Khanal et al., 2019).

Flood induced by TCs is the most frequent natural disaster in the eastern coastal region of China (Zhang et al., 2020). China's climate is mainly shaped by the East Asian Monsoon. The East Asian typhoon season is characterized by heavy inland rainfall and high storm tide, which are the major driving factors of coastal flood hazards in China. The slowdown in forward speed of landfalling TCs in the Northwest Pacific over 1949-2015 had increased the risk of flooding from water 65 level and rainfall even without considering the changes in storm strength (Kossin, 2018). The simultaneous and/or consecutive occurrence, both in time and space, of heavy rainfall and high tide can lead to compound flooding (Wahl et al., 2015; Bilskie et al., 2021). Furthermore, the risk posed by the interactions between hydro-meteorological events under the 
condition of sea level rise and changing tidal regimes is bound to increase in the future (Idier et al., 2020). Despite the increasing threat of compound flooding events along the Chinese coast, owing to the unavailability of water level records during typhoon events, the associated joint probabilities and driving mechanisms have not been explored (Fang et al., 2020). This research intends to fill this important niche.

The TCs often produce strong onshore winds and low barometric pressure, which would cause extreme storm surge, at the same time, generate heavy rainfall on the coastal region (Hoque et al., 2018; Sohn et al., 2021). Peak water level during TCs not only results from the combination of storm surge and astronomical tide. Additionally, the combination of absolute sea

75 level rise (SLR) due to the global warming and land subsidence due to urbanization has caused relative sea level rise (RSLR) (IPCC, 2021; Jebbad et al., 2022). According to the Regulations of Shanghai Municipality on the Administration of Land Subsidence Prevention and Control, the land subsidence rate was $6.19 \mathrm{~mm} / \mathrm{yr}$ from 1965 to 2001. Since 2001, the land subsidence rate has been controlled to varying degrees by adaptation measures such as recharging water to aquifers.

This study establishes the joint distribution of water level and rainfall during typhoon season in the Shanghai estuary region,

80 with the aim to better understand the risk of compound flooding and to improve the assessment of flood-defence design standard for adaptation strategies. Our modeling framework couples a state-of-the-art hydrodynamic model and statistic model. This model coupling enables us to quantify the joint distribution of rainfall and storm surge events during typhoon season, and also to consider the comparative cases with and without RSLR for Shanghai. The procedure of the modeling framework is as follows. First, the peak water levels, consisting of astronomical tides, storm surges associated with TCs, and RSLR, in Shanghai over 1961-2018 are generated using the Delft3D-Flow Flexible Mesh model, then a compound hazard scenario for deriving design values is chosen. Second, we compare and investigate the peak water level with and without RSLR, and select the extreme compound flood events according to the design standard of the joint hazard scenario. Finally, we analyse the contribution of storm surge, astronomical tide and RSLR to peak water level based on the top seven extreme compound flood events over the study period. We provide a framework that could be applied to other coastal cities which face the similar constraint of unavailable water level records. The findings from our research could be useful for decisionmaking in developing coastal flood defence measures in Shanghai and other East Asian coastal cities. This is the major contribution of this research.

\section{Materials and Methods}

\subsection{Study Area}

95 Shanghai is surrounded by water on three sides, and the Huangpu River and Suzhou River pass through the city (Figure 1). The total area of Shanghai is $6,340.5 \mathrm{~km}^{2}$ with a population of 24.87 million in 2020 . The annual rainfall is around 1,200 $\mathrm{mm}$. June to September are the rainy months. From late August till early September, Shanghai is frequently affected by typhoons and rainstorms (Yin et al., 2021). Storm flooding caused by typhoons is the main natural disaster in Shanghai. Shanghai's flood risk is about US $\$ 63$ million/year under an optimistic scenario of a maximum protection level of 1/1000 per 
https://doi.org/10.5194/nhess-2022-26

Preprint. Discussion started: 25 January 2022

(c) Author(s) 2022. CC BY 4.0 License.

(c) (1)

100 year (Hallegatte, Green, Nicholls, \& Corfee-Morlot, 2013). Although the construction of flood control measures in the past 50 years has effectively reduced the risk of storm floods, TC Matsa in 2005, the 2013 TC Fitow, and the 2019 TC Lekima caused substantial losses in Shanghai. Particularly, typhon Winnie in 1997 led to an economic damage of over US \$100 million. During typhoon Winnie period, the water level at Huangpu Park (city center) rose to $5.72 \mathrm{~m}$, equivalent to the water level with a 500-year return period. During typhon Fitow in 2013, the water level at Mishidu in the inland area of the

105 Huangpu River was recorded at WD (Wusong Datum is adopted as the reference) as $4.61 \mathrm{~m}$, which broke the record (Ke et al., 2018). In the context of climate change, relative sea level rise, and urban expansion, Shanghai will face greater compound flood risks and challenges from TCs, storm surge, and extreme rainstorm in the future (Wang et al., 2018).

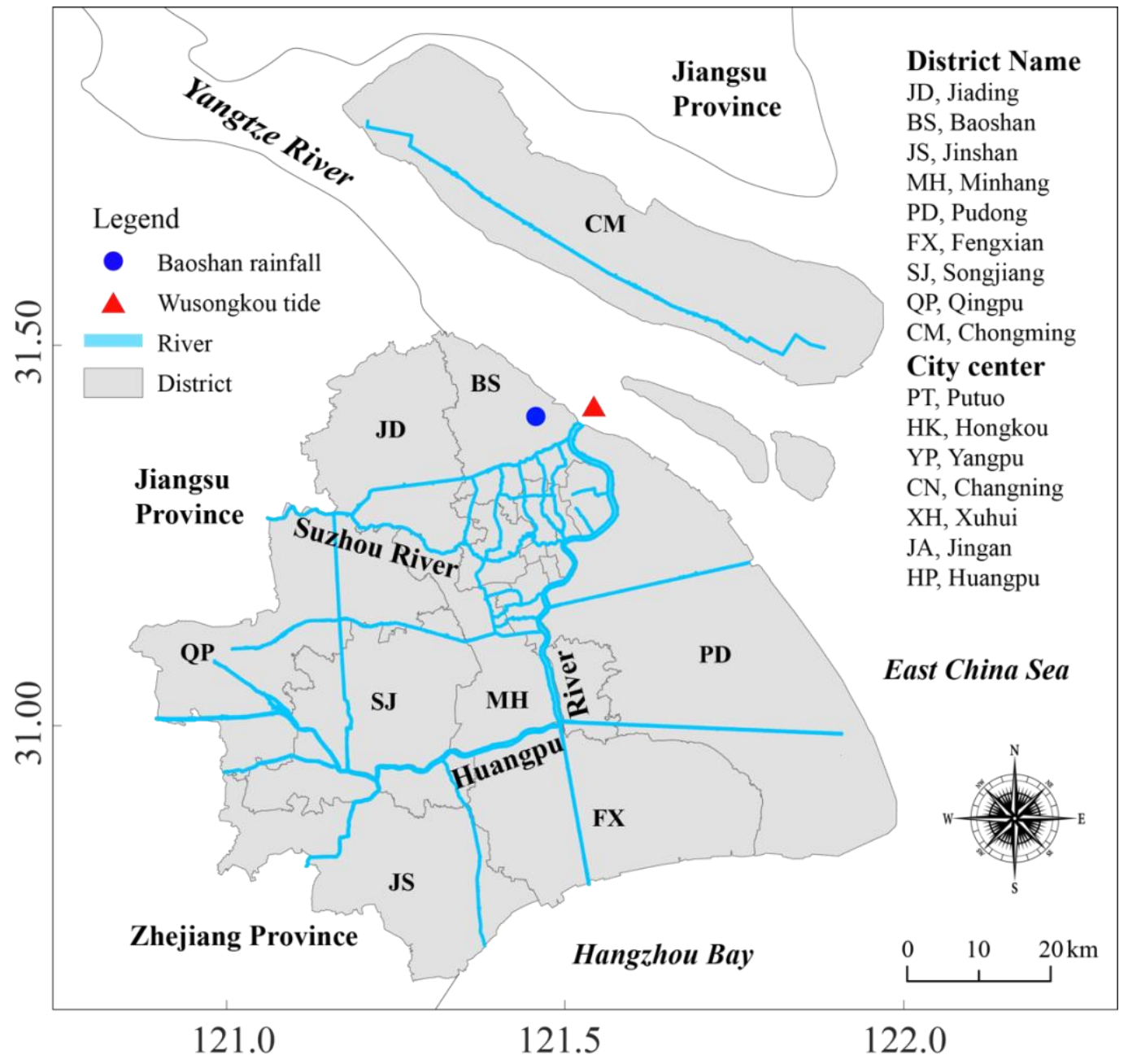

Figure 1: Location map of Shanghai. 
$110 \quad 2.2$ Data

This study systematically collected the geographic and meteorological data of the study area, including TC tracks (19612018), and daily accumulated rainfall (1961-2018). Due to the unavailability of measured water level data from historical TCs, in this study we evaluate the dependence coefficient between rainfall and water level based on observed rainfall and simulated peak water level during TCs. Observations come from a set of rain gauge measurements. Modelled data consist of

115 data sets created using the International Best Track Archive for Climate Stewardship (IBTrACS) from NOAA's National Climatic Data Center.

We use the Delft3D-Flow model (Knapp et al., 2010) to simulate water level during TC periods. IBTrACS contains 6-hourly TC centre's longitude and latitude, minimum central pressure $\left(P_{c}\right)$ and sustained maximum surface wind velocity $\left(V_{\max }\right)$. Multiple agencies provide TC best tracks in the West Pacific, and we opt to use the best track from Hong Kong Observatory 120 (www.hko.gov.hk). This choice was made because it includes the most complete set of observations from TCs making landfall in China (Chen et al., 2011).

We analysed the historical TCs influencing Shanghai between 1961 and 2018. We first defined a 6-degree-latitude square box around Shanghai (Figure 2). The area covered by the blue box can be regarded as an alert area in terms of a TC causing potential damage in Shanghai. The size of the blue box was designed to be just large enough to include the partial tracks of 125 the top 10 most costly TCs for Shanghai since 1949 (personal communication with Shanghai Climate Centre). We then selected historical TCs lasting for at least 24 hours in the blue box. After this best-track pre-processing, 210 TCs for the period of 1961-2018 are selected in this study (Figure 2). Additionally, we obtained tidal level data (1997) at the Wusongkou tide gauge from the Shanghai Municipal Water Authority, which are used for hydrodynamic model validation. 


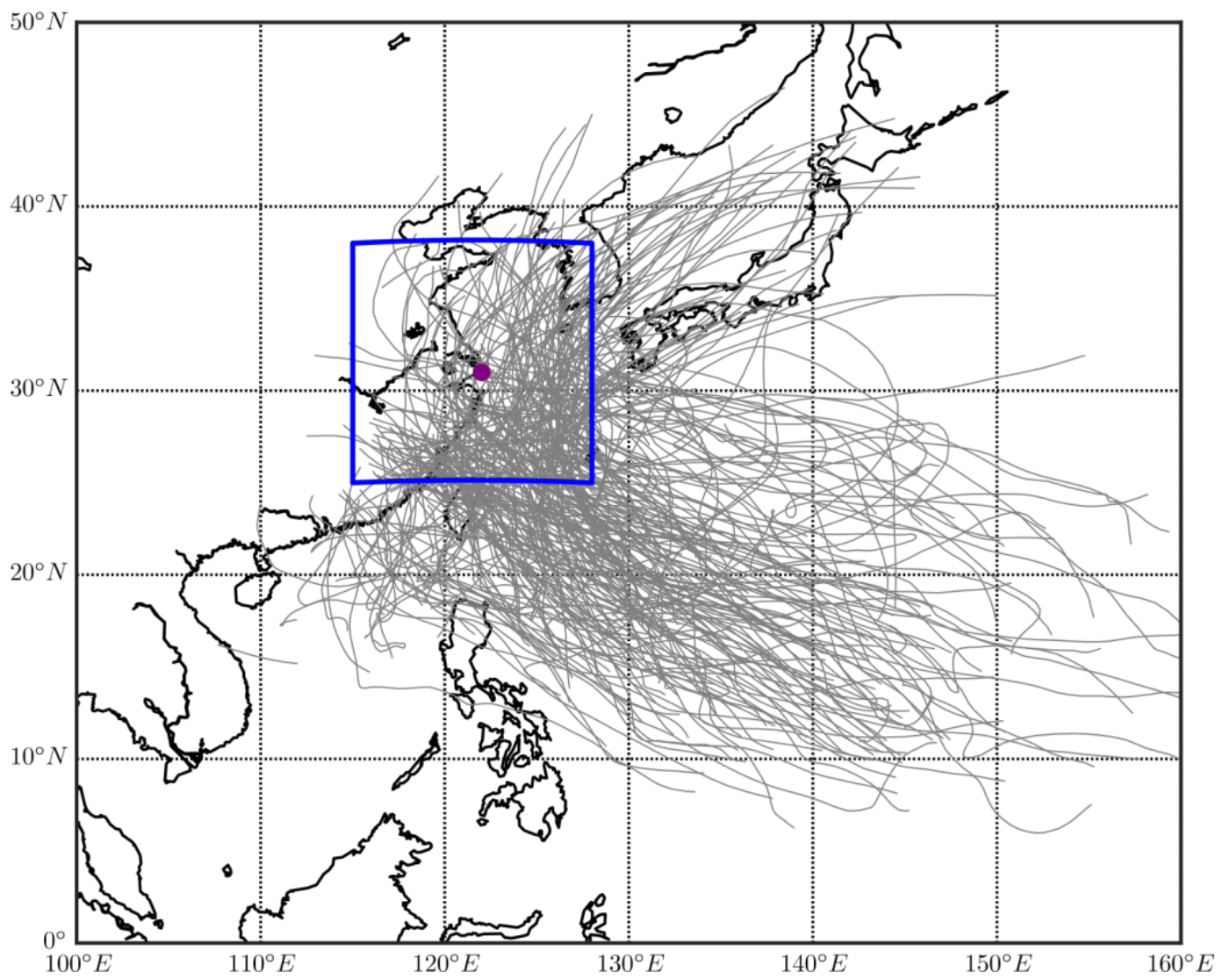

Figure 2: Location map for the area of interest. (Grey colored lines indicate major historical typhoon tracks within the region. Blue box indicates the selection criteria.)

Daily rainfall records from 1961 to 2018 are collected from the China Meteorological Administration (CMA, http://data.cma.cn) for the Baoshan gauge station, being the closest to the Wusongkou surge station (Figure 1). The annual precipitation in Shanghai is $1,200 \mathrm{~mm}$ with the rainiest months being from June through September. Rainfall data are used in this study to approximate the TC-induced runoff. To implicitly account for the rainfall travel time to the catchment outlet, 1-, 2-, and 3-days accumulated rainfall were also estimated and the correlation between such accumulated rainfall and peak water level was then estimated.

According to the Chinese Sea Level Bulletin of 2020, which was compiled by the State Oceanic Administration of China, the absolute sea-level rose at a rate of $3.4 \mathrm{~mm} / \mathrm{yr}$. According to the Regulations of Shanghai Municipality on the Administration of Land Subsidence Prevention and Control, the land subsidence rate was $27.93 \mathrm{~mm} / \mathrm{yr}$ from 1921 to 1964. From 1965 to 2001, the land subsidence rate was $6.19 \mathrm{~mm} / \mathrm{yr}$. After 2001, the land subsidence rate has been under varying extents of control by adaptation measures such as recharging water to aquifers, and in most regions being 5-15 mm/yr. We use $10 \mathrm{~mm} / \mathrm{yr}$ as the land subsidence rate from 2001 to 2018. The downside of such an assumption is that it fails to consider 
https://doi.org/10.5194/nhess-2022-26

Preprint. Discussion started: 25 January 2022

(c) Author(s) 2022. CC BY 4.0 License.

(c) (1)

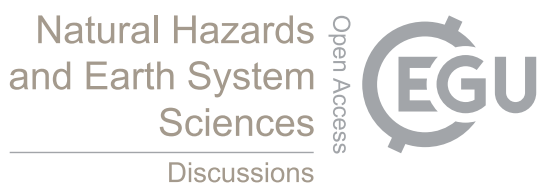

possible accelerating factors such as population growth, vertical and horizontal urban expansion, and deep strata motions,

145 but these complex factors are beyond the scope of this research.

\subsection{The framework}

The objectives of this study are to overcome the limitation of unavailable water level records during TCs and set up a framework to improve the methods for selecting the most suitable TCs for the research and for investigating TCs' influence on storm tide. Due to the limited storm tide data availability, we employ an empirical track model for pressure and wind

150 fields, followed by a physics-based ocean model to simulate storm tide and astronomical tide during typhoon season in Shanghai. A numerical simulation is carried out to better understand the distribution and timing of the peak storm tide and the areas of the country affected. The surge model was calibrated using the recorded atmospheric pressure and focused on ones with the most severe damages, comparing well with the results of the field survey data (Ke et al., 2021). Following this, the copula function was used to connect peak water level with rainfall and construct a joint distribution. After that, we compare and investigate difference between peak water level and rainfall under the effect of RSLR, and select the extreme compound flood events according to the design value of the joint hazard scenario. Finally, we analyse the contribution of storm surge, astronomical tide and RSLR to peak water level (Figure 3). 


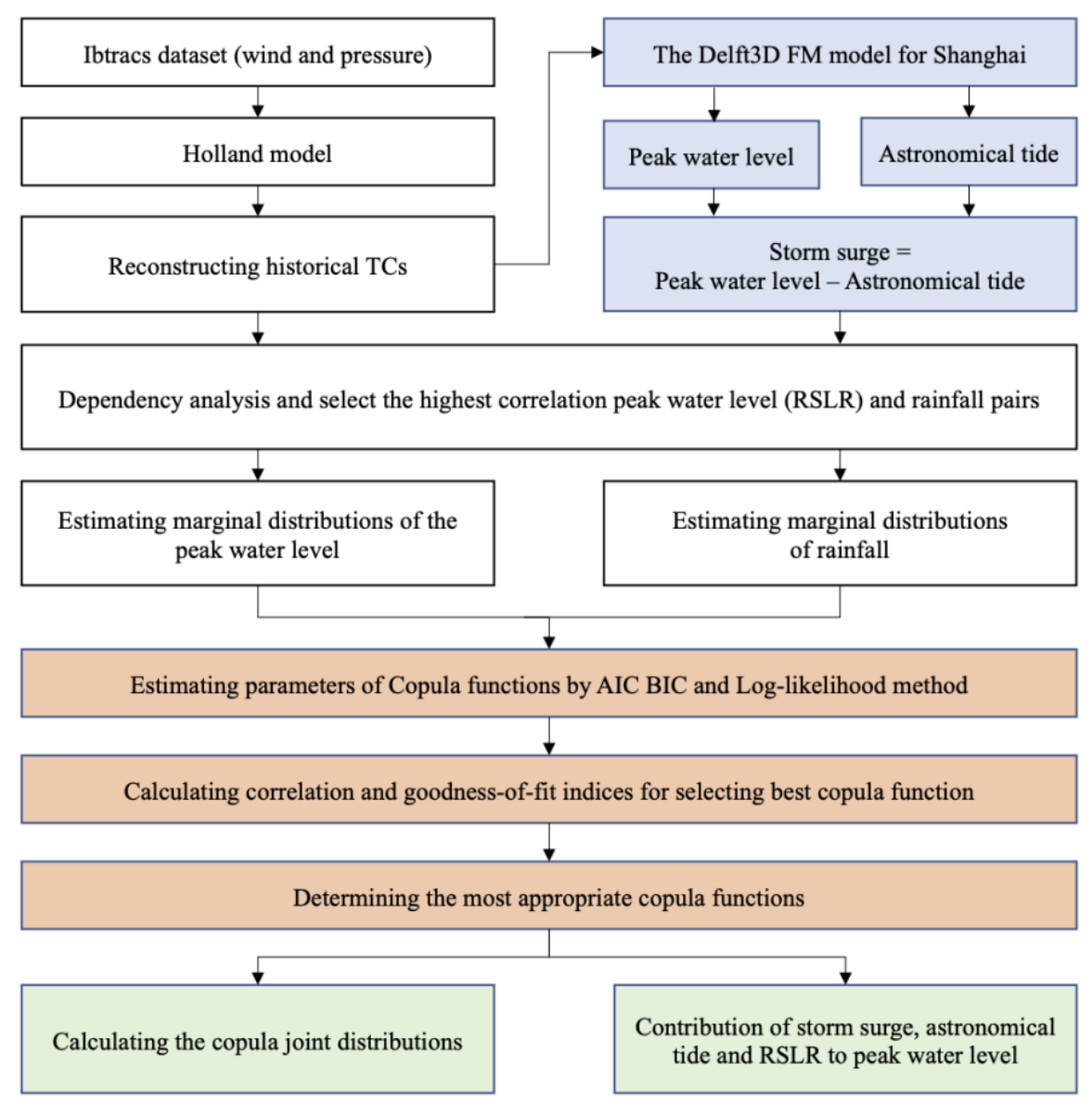

Figure 3: Flowchart of this study.

\subsection{Delft3D-Flow Flexible Mesh model}

Delft3D WES (Wind Enhance Scheme), a built-in module in Delft3D, is used in this study to generate wind fields of TC scenarios. WES calculates the wind and pressure according to the Holland formula (Holland et al., 2010). It is able to generate tropical cyclone wind and pressure fields around storm center positions on a high-resolution grid. Through asymmetry, WES has been slightly improved. This asymmetry is caused by the use of the translational speed of the cyclone's center displacement as the steering flow, and the rotation of the wind velocity due to friction (Takagi and $\mathrm{Wu}$, 2016). The output of WES is suitable as input for the Delft3D-Flow model to simulate water level including the effect of storm surge.

The hydrodynamic model Delft3D-Flow Flexible Mesh is employed in this study to solve multi-disciplinary problems in coastal, river, and estuarine environments (Deltares, 2013). The domain of the model covers the East China Sea, Hangzhou

170 Bay, the Yangtze Estuary, and the downstream reach of the Yangtze River, ranging from 24 to $34^{\circ} \mathrm{N}$ and 118 to $128^{\circ} \mathrm{E}$, and consists of 69,000 mesh cells. The model has been validated with observed storm tide and astronomical tide at 10 stations 
around Shanghai during TC Winnie in 1997 (Ke et al., 2021). The storm tide and astronomical tide of 210 TCs are calculated in this Delft3D-Flow Flexible Mesh model. Then, the peak storm tide is selected from each TC. In addition, the storm surge is calculated by using storm tide minus astronomical tide at the same time of peak storm tide. In this study, we assume the Yangtze River discharge equals its annual mean at $31000 \mathrm{~m}^{3} / \mathrm{s}$.

\subsection{Dependence modelling and design value via copulas}

We define the joint distribution of rainfall and water level, $F_{R, W L}$ as $F_{R, W L}=C\left(F_{R}, F_{W L}\right)$ where $F_{R}$ and $F_{W L}$ are marginal distributions of rainfall and water level, and $C$ is the associated dependence function, i.e., copula, modelling the dependence between rainfall and water level independently from their marginal distributions (Sklar, 1973; Salvadori and De Michele, 2004). Hence, we select marginal distributions among the most commonly used distribution functions for extremes, namely: Generalized Extreme Value (GEV), Pearson type III (P-III), Gumbel, Exponential and Weibull.

The copula function raised by Sklar can model the dependence structure and joint probability distributions. The Gaussian, Clayton, Frank and Gumbel copula functions are selected to establish joint distribution between water level and rainfall. To evaluate the fitting error and select the appropriate copula function by the non-parametric estimation method, the Akaike information criterion (AIC), Bayesian information criterion (BIC) and root mean square error (RMSE) are employed.

$A I C=-2 \iota\left(\theta^{\wedge} \mid y\right)+2 K$

$B I C=-2 \iota\left(\theta^{\wedge} \mid y\right)+K \ln (n)$,

$K$ is the number of estimated parameters in the model including the intercept and $\iota\left(\theta^{\wedge} \mid y\right)$ is the $\log$-likelihood at its maximum point of the estimated model; $n$ is the sample size. The rule of selection was that the smaller the value of AIC was, the better the model was, and similarly with the BIC.

$R M S E=\sqrt{\frac{1}{n} \sum_{i=1}^{n}\left(X_{C}(i)-X_{O}(I)\right)^{2}}$,

where $n$ is the number of observations; $X_{C}$ is the theoretical probability from the copula and $X_{O}$ is the empirical observed probability. It is also worth noting that the dependence between rainfall and water level is given by their linear correlation, i.e., Spearman's $\rho$, or concordant/discordant pairs, i.e. Kendall $\tau$.

195 Following Salvadori and De Michele (2004), copulas allow a straightforward definition of two hazard scenarios, i.e, pairs with an occurrence probability greater than a safety threshold, namely "AND" and "OR" scenarios. The "AND" scenario assumes that a hazardous condition is realized when both the dependent variables, in this case rainfall and water level, exceed their predefined thresholds, while the "OR" scenario assumes that a hazardous condition can occur when either one of the two dependent variables exceed their predefined thresholds. The "AND" scenario is commonly used for compound flooding mostly because the flooding can be generated by excessive runoff, high sea level, or a combination of both 
(Moftakhari et al., 2017; Moftakhari et al., 2019; Zellou and Rahali, 2019). The joint exceedance probability based on the “AND” scenario is given by Eq. (4).

$P((U>u d) \cap(V>v d))=1+u_{d}+v_{d}-C\left(u_{d}, v_{d}\right)$,

where $U=F_{R}$ and $V=F_{W L}$ are the marginal distributions and $u_{d}$ and $v_{d}$ are the safety threshold of rainfall and water level respectively. The dependent design values $\left(R_{d}=\left(F_{r}-1\right)\left(u_{d}\right), W L_{d}=\left(F_{W L}-1\right)\left(v_{d}\right)\right)$ can be inferred from Eq. (4) based on the level of safety desired.

The joint probability cannot be directly used as the reference value of the actual engineering fortification standard. We calculate the joint design value combinations with the joint return period, which can serve as a reference for the engineering design. For given peak water level and rainfall events, under the conditions of a given joint return period, we design a series

210 of $\left(u_{d}, v_{d}\right)$ combinations to maximize $P\left(\left(U>u_{d}\right) \cap\left(V>v_{d}\right)\right)$, thereby obtaining the optimal combination design value. In the practical calculation, the intersection of the diagonal of critical probabilistic surface and probability isoline is regarded as the design values of $\left(u_{d}, v_{d}\right)$.

\section{Results}

\subsection{Effect of RSRL to peak water level}

215 The correlation between extreme water level and rainfall is positive (Table S1). The extreme water level and 2-days accumulated rainfall have the highest correlation compared with 1-days and 3-days accumulated rainfall. The correlation between water level and rainfall is significant $\left(P_{\text {value }}<0.05\right)$ in all cases. Consequently, the remaining analysis will be performed considering 2-days cumulative rainfall, here after $R_{2 d}$.

Probability density function is a useful tool for comparing peak water levels between the cases with and without RSLR.

220 Results in Figure 4 shows a clear shift in the distribution of peak water level during the TC periods. It demonstrates that RSLR increases both the mean and variance of peak water levels, thus resulting in higher risk of flooding in Shanghai. 


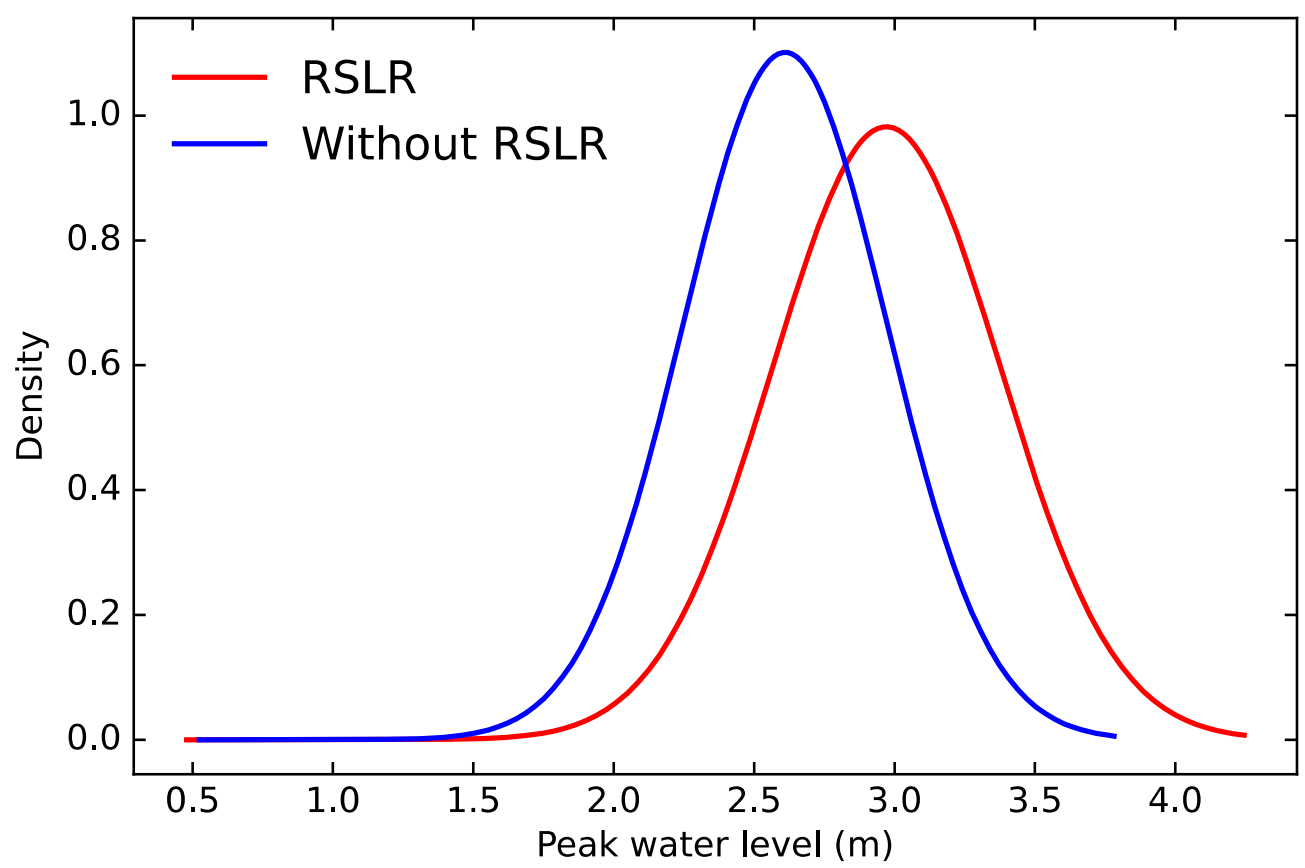

Figure 4: The shift of the probabilistic distribution of peak water level, "with RSLR" versus "without RSLR", in Shanghai during 1961-2018.

225 The marginal distributions are used to transform water level and $R_{2 d}$ into uniform marginals, $u_{W L}$ and $u_{R 2 d}$, respectively. Then, the preferred copula is selected among the Clayton, Frank, Gumbel and Gaussian copula. In the case without considering RSLR, the preferred copula is Clayton because it has the smallest AIC, BIC, and RMSE (the upper panel in Table 1). In the case with the presence of RSLR, the lower panel in Table 1 shows that Gaussian copula has the smallest AIC, BIC, and RMSE. Therefore, Gaussian copula is selected as the best fit for the peak water level and rainfall under the 230 effect of RSLR. Figure 5 shows the dependence structure between water level and rainfall with RSLR and without RSLR.

Table 1. Performance measures of the estimated copula functions

\begin{tabular}{cccccc}
\hline & Copula type & Max-likelihood & AIC & BIC & RMSE \\
\hline \multirow{4}{*}{ Without } & Gaussian & 1024.1 & -2046.1 & -2042.8 & 0.1105 \\
$R S L R$ & Clayton & 1034.7 & -2067.5 & -2064.1 & 0.1050 \\
& Frank & 1009.4 & -2016.8 & -2013.4 & 0.1185 \\
& Gumbel & 972.0 & -1941.1 & -1938.7 & 0.1415 \\
\hline \multirow{2}{*}{$\begin{array}{c}\text { Presence of } \\
R S L R\end{array}$} & Gaussian & 1038.8 & -2075.5 & -2072.2 & 0.1030 \\
& Clayton & 1029.4 & -2056.7 & -2053.4 & 0.1077 \\
& Frank & 1016.4 & -2030.9 & -2027.5 & 0.1146 \\
& Gumbel & 992.7 & -1983.5 & -1980.2 & 0.1282 \\
\hline
\end{tabular}




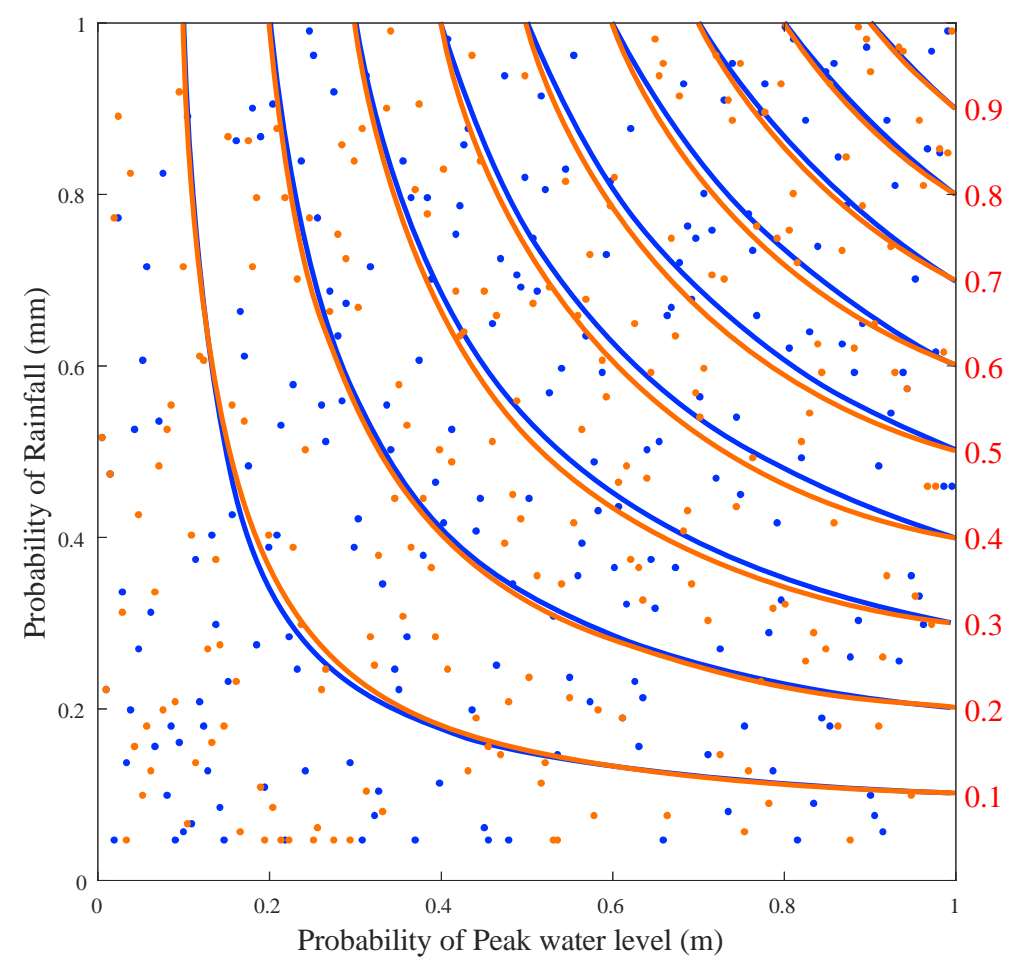

Figure 5: Copulas difference between RSLR (yellow) and without RSLR (blue). The isolines are the fitted Gaussian copula. Numbers on the right side is the joint probability value of isolines.

\subsection{Contribution of storm surge, astronomical tide and RSLR to peak water level}

Figure 6 presents the scatter plot of peak water level and rainfall with and without RSLR. It shows that the influence of RSLR pushes up the design value of peak water level from $3.25 \mathrm{~m}$ to $3.36 \mathrm{~m}$ under the 10 -yr joint return period, with the corresponding design value of rainfall at $90.39 \mathrm{~mm}$. The traditional approach is to assume independence between rainfall and sea level, then the independence assumption would generally lead to lower design values compared to scenarios from the copula-based method. It usually depends on how one selects the pairs and the statistical model used (independent/dependent). This is a direct consequence of the difference in the sampling of extreme observations between both approaches. 


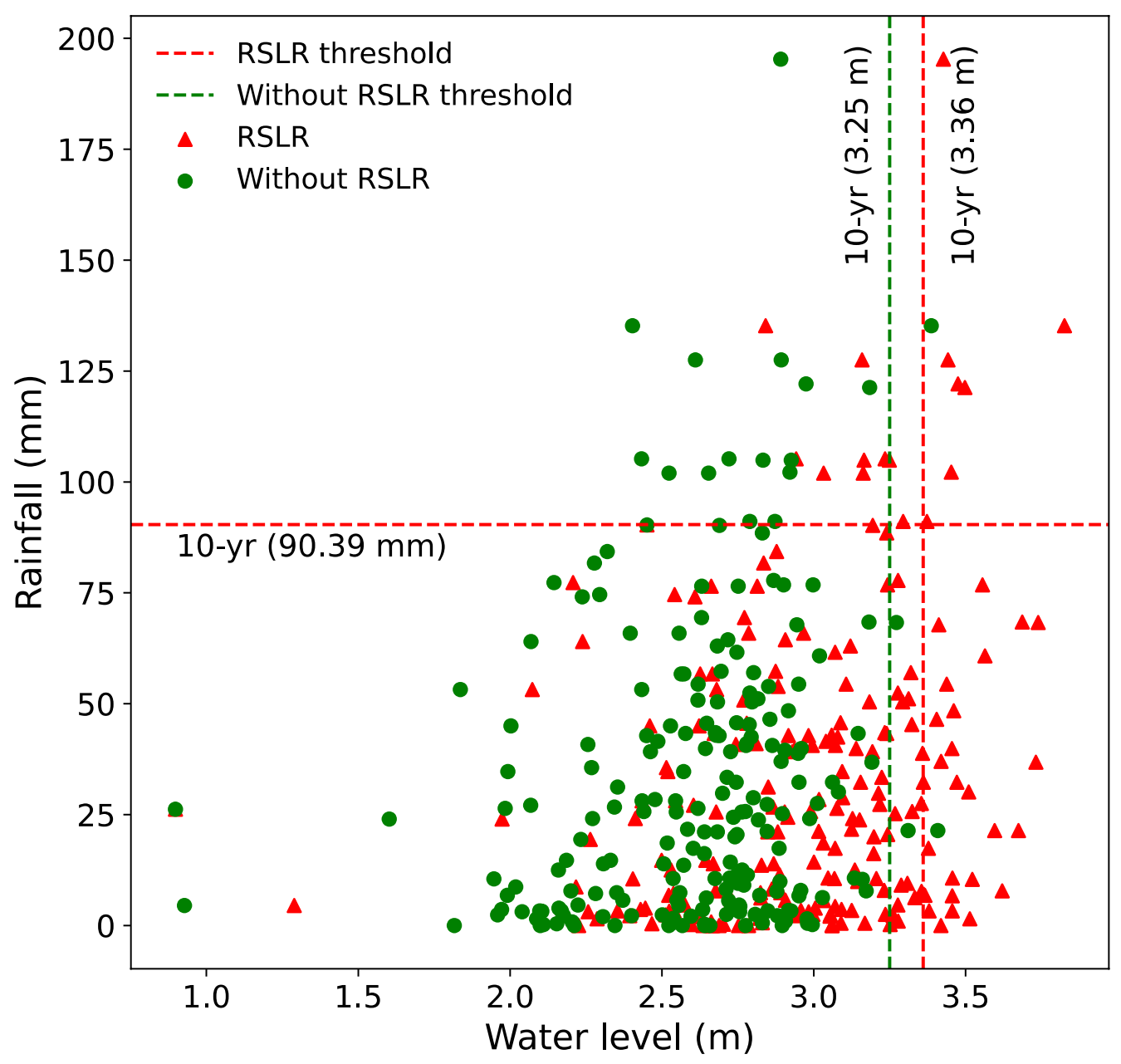

Figure 6: Scatter plot of water level and rainfall analysed. Red lines show the design value of 10-yr joint return period with effect of RSLR. Green lines show the design value of 10 -yr joint return period without effect of RSLR.

Based on the results in Figure 6, we defined the compound flood events as the peak water level and rainfall both being greater than their design values of 10-yr joint return period (i.e., peak water level > $3.36 \mathrm{~m}$ and rainfall $>90.39 \mathrm{~mm}$ ). Based on this criterion, we identified seven compound flood events under the influence of RSLR (Figure 7).

Peak water level results from the combination of storm surge, astronomical tide and RSLR. Figure 7 shows the contribution of storm surge, astronomical tide and RSLR to peak water level from the seven extreme compound flood events in Shanghai. We consider the cases including the effect of RSLR and split the peak water level according to the contributions of its components, i.e., storm surge, astronomical tide, and RSLR, to investigate their shares of contribution.

Overall, storm surge explains $32 \%$ of the peak water level, while astronomical tide account for 55\% and RSLR account for

$25513 \%$ of the peak water level. The astronomical tide is in general the leading contributor to the peak water level, but storm surge can be the leading contributor in some cases, e.g., TC 4 , in which the contribution of storm surge accounted for $45 \%$ of 
peak water level. Under the scenario of future global warming and further urbanization, the impact of RSLR would increase and should not be treated as less important.

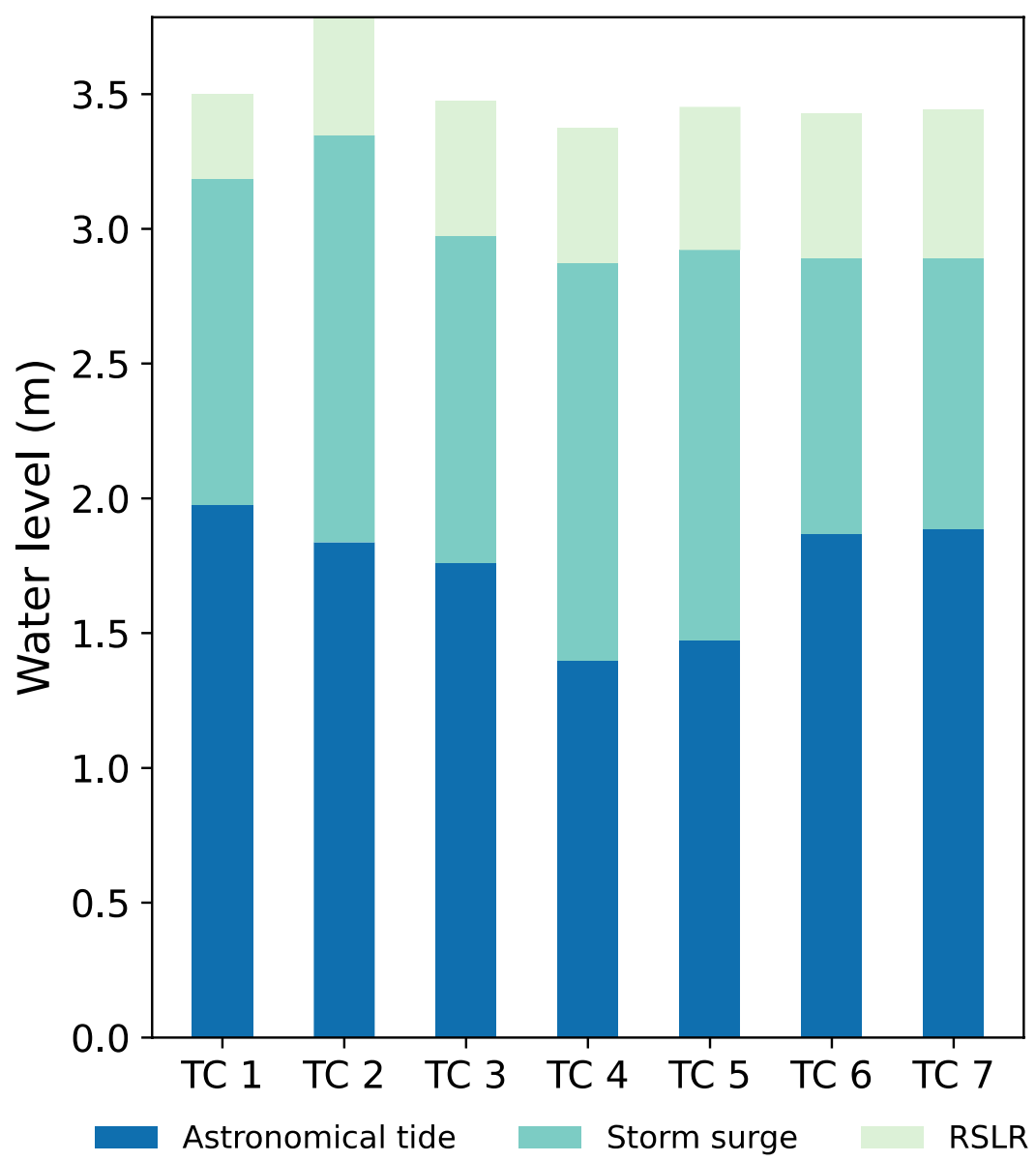

Figure 7: The contribution of storm surge, astronomical tide and RSLR to peak water level. (Cases are samples greater than 10-yr joint return period.)

\section{Conclusions}

It is important to consider the compounding effects of multiple interdependent extremes or drivers to accurately characterize the underlying hazard. In this study, we focused on the joint impact of peak water level and rainfall in Shanghai, a coastal mega-city located in the Yangtze River Delta region. We showed that Shanghai is prone to compound flooding and this justifies the adoption of a probabilistic modelling framework to incorporate the interdependence of multiple flood-drivers. Between 1961 and 2018, the RSLR had increased by $0.55 \mathrm{~m}$ in Shanghai. With the on-going global warming and further urbanization vertically and horizontally in the city, the process of RSLR would continue and amplify the peak water levels in extreme flooding events. The sample data we consolidated show an increase in the probability of peak water level under the 
effect of RSLR. We also identify the extent of shift in the joint distribution of peak water level and rainfall during TC periods between the theoretical setting without RSLR and the real setting with RSLR by employing the best fitted copula functions. The shift indicates that the RSLR lead to an increase in both the mean and variance of peak water levels, thus a significantly higher level of flooding risk in Shanghai.

The design value of peak water level and rainfall are $3.36 \mathrm{~m}$ and $90.39 \mathrm{~mm}$ during TCs period under the 10-yr joint return

275 period and with the influence of RSLR. We selected the potential compound flood events according to this pair of design value and identified seven potential compound flood events. The analysis of these seven events shows that astronomic tide is in general the most important driver of the peak water level, however, there is one case in which storm surge is the leading driver of the peak water level. If the astronomic tide relative to mean high water instead of mean sea level, the length of the tide part bars may be smaller. However, we argue that the peak water level is the most dangerous hazard to coastal cities.

280 The combination of astronomical tide, storm surge and RSLR drives the peak water level. We cannot neglect the contribution of tide during the typhoon season.

The framework developed in this study could be applied to other coastal regions in East and Southeast Asia. The impact of the RSLR in amplifying the peak water levels would significantly increase in the future. Therefore, the monitoring and prediction of the RSLR should be an important component in the development of the future design standards for flood

285 preparedness. Furthermore, RSLR caused by climate change and intensive use of urban land would also increase social vulnerability, which can be an interesting topic for future research.

\section{Data availability}

IBTrACS data were obtained from the NOAA National Centers for Environmental Information from their website at https://www.ncdc.noaa.gov/ibtracs. Daily rainfall records from 1961 to 2018 are collected from the China Meteorological

290 Administration (CMA, http://data.cma.cn).

\section{Competing interests}

The authors declare that they have no conflict of interest.

\section{Acknowledgments}

This work is sponsored by the National Key R\&D Program of China (Grant no. 2019YFE0124800); National Natural 295 Science Foundation of China (Grant number: 51761135024 and 41971199), Netherlands Organization for Scientific Research (NWO) (Grant no. ALWSD.2016.007), the Engineering and Physical Sciences Research Council of the UK (Grant Nos. R034214/1); and also the Shanghai Science and Technology Support Program (Grant No. 19DZ1201505), the Major 
Program of National Social Science Foundation of China (Grant No. 18ZDA105), and the ECNU Academic Innovation Promotion Program for Excellent Doctoral Students (YBNLTS2020035). the High-level Special Funding of the Southern University of Science and Technology (Grant No. G02296302, G02296402). Thankful for financial support from the program of China Scholarships Council (No.202006140040).

\section{References}

Anandalekshmi, A., Panicker, S. T., Adarsh, S., Siddik, A. M., Aloysius, S., Meh jabin, M. (2019). Modeling the concurrent

305 impact of extreme rainfall and reservoir storage on kerala floods 2018: a copula approach. Modeling Earth Systems and Environment, 5(4), 1283-1296.

Bevacqua, E., Maraun, D., Hobæk Haff, I., Widmann, M., Vrac, M. (2017). Multivariate statistical modelling of compound events via pair-copula constructions: analysis of floods in ravenna (italy). Hydrology and Earth System Sciences, 21(6), 2701-2723.

310 Bevacqua, E., Maraun, D., Vousdoukas, M. I., Voukouvalas, E., Vrac, M., Mentaschi, L., Widmann, M. (2019). Higher probability of compound flooding from precipitation and storm surge in europe under anthropogenic climate change. Science advances, 5(9), eaaw5531.

Balistrocchi, M., Moretti, G., Orlandini, S., Ranzi, R. (2019). Copula-based modeling of earthen levee breach due to overtopping. Advances in Water Resources, 134, 103433.

315 Bevacqua, E., Vousdoukas, M. I., Shepherd, T. G., Vrac, M. (2020). Brief communication: The role of using precipitation or river discharge data when assessing global coastal compound flooding. Natural Hazards and Earth System Sciences, 20(6), 1765-1782.

Bilskie, M. V., Zhao, H., Resio, D., Atkinson, J., Cobell, Z., Hagen, S. C. (2021). Enhancing flood hazard assessments in coastal louisiana through coupled hydrologic and surge processes. Frontiers in Water, 3, 5.

320 Chen, X., Wu, L., Zhang, J. (2011). Increasing duration of tropical cyclones over 432 china. Geophysical Research Letters, $38(2)$.

Couasnon, A., Eilander, D., Muis, S., Veldkamp, T. I., Haigh, I. D., Wahl, T., Ward, P. J. (2020). Measuring compound flood potential from river discharge and storm surge extremes at the global scale. Natural Hazards and Earth System Sciences, 20(2), 489-504.

325 Couasnon, A., Sebastian, A., Morales-N'apoles, O. (2018). A copula-based bayesian network for modeling compound flood hazard from riverine and coastal interactions at the catchment scale: An application to the houston ship channel, texas. Water, 10(9), 1190.

Chao, S. R., Ghansah, B., Grant, R. J. (2021). An exploratory model to characterize the vulnerability of coastal buildings to storm surge flooding in Miami-Dade County, Florida. Applied Geography, 128, 102413. 
Deltares, D. (2013). Delft3D-Flow user manual. Deltares Delft, The Netherlands.

Du, S., Scussolini, P., Ward, P. J., Zhang, M., Wen, J., Wang, L. (2020). Hard or soft flood adaptation? advantages of a hybrid strategy for shanghai. Global Environmental Change, 61, 102037.

Fang, J., Wahl, T., Fang, J., Sun, X., Kong, F., Liu, M. (2020). Compound flood potential from storm surge and heavy precipitation in coastal china. Hydrology and Earth System Sciences Discussions, 1-24.

Feng, D., Beighley, E. (2020). Identifying uncertainties in hydrologic fluxes and seasonality from hydrologic model components for climate change impact assessments. Hydrology and Earth System Sciences, 24(5), 2253-2267.

Girgin, S., Necci, A., Krausmann, E. (2019). Dealing with cascading multi-hazard risks in national risk assessment: the case of natech accidents. International journal of disaster risk reduction, 35, 101072.

Holland, G. J., Belanger, J. I., Fritz, A. (2010). A revised model for radial profiles of hurricane winds. Monthly weather

340 review, 138(12), 4393-4401.

Hoque, M. A. A., Phinn, S., Roelfsema, C., Childs, I. (2018). Assessing tropical cyclone risks using geospatial techniques. Applied geography, 98, 22-33.

Hu, H., Tian, Z., Sun, L., Wen, J., Liang, Z., Dong, G., Liu, J. (2019). Synthesized trade-off analysis of flood control solutions under future deep uncertainty: An application to the central business district of shanghai. Water research, 166,

345115067.

Hendry, A., Haigh, I., Nicholls, R., Winter, H., Neal, R., Wahl, T., Darby, S. (2019). Assessing the characteristics and drivers of compound flooding events around the uk coast. Hydrology and Earth System Sciences, 23, 3117-3139.

Idier, D., Rohmer, J., Pedreros, R., Le Roy, S., Lambert, J., Louisor, J., Le Cornec, E. (2020). Coastal flood: a composite method for past events characterisation providing insights in past, present and future hazards-joining historical, statistical

350 and modelling approaches. Natural Hazards, 101(2), 465-501.

IPCC. (2021). Climate change 2021: The physical science basis. contribution of working group to the sixth assessment report of the intergovern- mental panel on climate change [Book]. Cambridge, United Kingdom and New York, NY, USA: Cambridge University Press. Retrieved from www.climatechange2013.org.

Jebbad, R., Sierra, J. P., Mösso, C., Mestres, M., Sánchez-Arcilla, A. (2022). Assessment of harbour inoperability and

355 adaptation cost due to sea level rise. Application to the port of Tangier-Med (Morocco). Applied Geography, 138, 102623.

Ke, Q. (2014). Flood risk analysis for metropolitan areas-a case study for Shanghai. TU Delft: Delft University of Technology.

Ke, Q., Jonkman, S. N., Van Gelder, P. H., Bricker, J. D. (2018). Frequency analysis of storm-surge-induced flooding for the huangpu river in shanghai, china. Journal of Marine Science and Engineering, 6(2), 70.

360 Ke, Q., Yin, J., Bricker, J. D., Savage, N., Buonomo, E., Ye, Q. (2021). An integrated framework of coastal flood modelling under the failures of seadikes: a case study in shanghai. Natural Hazards, 1-33.

Khanal, S., Ridder, N., Terink, W., Hurk, B. v. d. (2019). Storm surge and extreme river discharge: A compound event analysis using ensemble impact modelling. Frontiers in Earth Science, 7, 224. 
Knapp, K. R., Kruk, M. C., Levinson, D. H., Diamond, H. J., Neumann, C. J. (2010). The international best track archive for climate stewardship (ibtracs) unifying tropical cyclone data. Bulletin of the American Meteorological Society, 91(3), 363376.

Kossin, J. P. (2018). A global slowdown of tropical-cyclone translation speed. Nature, 558(7708), 104-107.

Leonard, M., Westra, S., Phatak, A., Lambert, M., van den Hurk, B., McInnes, K., Stafford-Smith, M. (2014). A compound event framework for understand ing extreme impacts. Wiley Interdisciplinary Reviews: Climate Change, 5(1), 113-128.

Li, F., Zheng, Q. (2016). Probabilistic modelling of flood events using the entropy copula. Advances in Water Resources, 97, 233-240.

Li, M., Kwan, M. P., Yin, J., Yu, D., Wang, J. (2018). The potential effect of a 100-year pluvial flood event on metro accessibility and ridership: A case study of central Shanghai, China. Applied Geography, 100, 21-29.

Li, W., Wen, J., Xu, B., Li, X., Du, S. (2019). Integrated assessment of economic losses in manufacturing industry in

Shanghai metropolitan area under an extreme storm flood scenario. Sustainability, 11(1), 126.

Moftakhari, H. R., Salvadori, G., AghaKouchak, A., Sanders, B. F., Matthew, R. A. (2017). Compounding effects of sea level rise and fluvial flooding. Proceedings of the National Academy of Sciences, 114(37), 9785-9790.

Moftakhari, H., Schubert, J. E., AghaKouchak, A., Matthew, R. A., Sanders, B. F. (2019). Linking statistical and hydrodynamic modeling for compound flood hazard assessment in tidal channels and estuaries. Advances in Water

380 Resources, 128, 28-38.

Nicholls, R. J., Lincke, D., Hinkel, J., Brown, S., Vafeidis, A. T., Meyssignac, B., Fang, J. (2021). A global analysis of subsidence, relative sea-level change and coastal flood exposure. Nature Climate Change, 11(4), 338-342.

Paprotny, D., Sebastian, A., Morales-Nápoles, O., Jonkman, S. N. (2018). Trends in flood losses in Europe over the past 150 years. Nature communications, 9(1), 1-12.

385 Salvadori, G., De Michele, C. (2004). Frequency analysis via copulas: Theoretical aspects and applications to hydrological events. Water resources research, 40(12).

Santos, V. M., Casas-Prat, M., Poschlod, B., Ragno, E., van den Hurk, B., Hao, Z., Najafi, H. (2021). Statistical modelling and climate variability of compound surge and precipitation events in a managed water system: a case study in the Netherlands. Hydrology and Earth System Sciences, 25(6), 3595-3615.

390 Sklar, A. (1973). Random variables, joint distribution functions, and copulas. Kybernetika, 9(6), 449-460.

Sklar, M. (1959). Fonctions de Répartition à n Dimensions et Leurs Marges. Publ. inst. statist. univ. Paris, 8, 229-231.

Sohn, W., Bae, J., Newman, G. (2021). Green infrastructure for coastal flood protection: The longitudinal impacts of green infrastructure patterns on flood damage. Applied Geography, 135, 102565.

Takagi, H., Wu, W. (2016). Maximum wind radius estimated by the $50 \mathrm{kt}$ radius: improvement of storm surge forecasting 395 over the western north pacific. Natural Hazards and Earth System Sciences, 16(3), 705-717.

Visser-Quinn, A., Beevers, L., Collet, L., Formetta, G., Smith, K., Wanders, N., Thober, S., Pan, M., Kumar, R. (2019). Spatio-temporal analysis of compound hydro-hazard extremes across the UK. Advances in Water Resources, 130, 77-90. 
https://doi.org/10.5194/nhess-2022-26

Preprint. Discussion started: 25 January 2022

(c) Author(s) 2022. CC BY 4.0 License.

(c) (1)

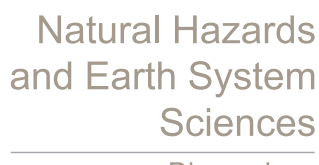

Discussions

Wahl, T., Jain, S., Bender, J., Meyers, S. D., Luther, M. E. (2015). Increasing risk of compound flooding from storm surge and rainfall for major us cities. Nature Climate Change, 5(12), 1093-1097.

400 Wang, J., Yi, S., Li, M., Wang, L., Song, C. (2018). Effects of sea level rise, land subsidence, bathymetric change and typhoon tracks on storm flooding in the coastal areas of shanghai. Science of the total environment, 621, 228-234.

Xu, H., Xu, K., Bin, L., Lian, J., Ma, C. (2018). Joint risk of rainfall and storm surges during typhoons in a coastal city of Hainan Island, China. International journal of environmental research and public health, 15(7), 1377.

Xu, P., Wang, D., Singh, V. P., Wang, Y., Wu, J., Lu, H., Zhang, J. (2019). Time-varying copula and design life level-based nonstationary risk analysis of extreme rainfall events. Hydrology and Earth System Sciences Discussions, 1-59.

Yin, J., Lin, N., Yang, Y., Pringle, W. J., Tan, J., Westerink, J. J., \& Yu, D. (2021). Hazard Assessment for TyphoonInduced Coastal Flooding and Inundation in Shanghai, China. Journal of Geophysical Research: Oceans, 126(7), e2021JC017319.

Zellou, B., Rahali, H. (2019). Assessment of the joint impact of extreme rainfall and storm surge on the risk of flooding in a 410 coastal area. Journal of Hydrology, 569, 647-665.

Zscheischler, J., Westra, S., Van Den Hurk, B. J., Seneviratne, S. I., Ward, P. J., Pitman, A. (2018). Future climate risk from compound events. Nature Climate Change, 8(6), 469-477.

Zhang, W., Chang, W. J., Zhu, Z. C., Hui, Z. (2020). Landscape ecological risk assessment of Chinese coastal cities based on land use change. Applied Geography, 117, 102174. 